\title{
Understanding the RNA-Specificity of HCV RdRp: Implications for Anti-HCV Drug Discovery
}

\author{
Jinyoung Kim ${ }^{\dagger}$ and Youhoon Chong ${ }^{p+r^{*}}$ \\ ${ }^{\dagger}$ Department of Biomedical Scienc'é and Technolog:, "Department of Molecular Biotechnology, \\ Konkuk Universit, Seonl 143-701, Korea. "E-mail: chongu(akonkuk.ackr \\ Received September 30,2005
}

\begin{abstract}
Unlike other viral polymerases, IICV RN $\Lambda$-dependent RNA polymerase (RdRp) has not been successliully inhibited by nucleoside analogues presumably due to its strong substrate specificity for RN $\Lambda$. Thus, in order to understand the RN $\Lambda$-specilicity ol'IICV RdRp, the structural characteristics ol the active site was investigated. The hereto unknown 2-OI I binding pocket at the active site ol RdRp provides invaluable implication lor the development of novel anti-IICV nucleoside analogues.
\end{abstract}

Key Words : HCV RNA-dependent RNA polymerase (RdRp). Nucleoside inhibitors, Molecular modeling, Drug design

\section{Introduction}

Hepatitis C virus (HCV) is the main agent responsible for contagious hepatitis not due to the "classical" hepatitis viruses $\mathrm{A}$ and $\mathrm{B} .^{2}$ There is presently no vaccine or widely effective treatment for the resulting liver damaging infection that can eventually lead to death. ${ }^{3}$ Because current $\mathrm{HCV}$ therapies are inefficient, costly and prone to producing debilitating side effects, $\mathrm{HCV}$ infection has been viewed as a growing threat to human health worldwide and therefore, new antiviral therapies are clearly needed.

Among the viral proteins encoded by HCV, the NS5B RNA-dependent RNA polymerase $(\mathrm{RdRp})^{\mathbf{4 - 7}}$ is an essential enzyme for viral replication and therefore represents a valid target for therapeutic intervention through the design of specific inhibitors. As the knowledge regarding HCV RdRp structure and function accumulates, development of specific inhibitors has been greatly promoted. However, in general, HCV RdRp is not sensitive to most nucleoside/tide analogs that inhibit other viral polymerases: it was not inhibited by most of the known inhibitors for DNA-dependent LNA polymerases (DdDp) or reverse transcriptases (RT). ${ }^{8-10}$ In this context, it is worth while to note that HCV RdRp is a RNA-specific enzyme whereas DdDp and RT take deoxyribonucleotides (DNA) as substrates. More interestingly, the most potent inhibitors of $\mathrm{HCV}$ RdRp discovered to date are 2 '-substituted nucleoside analogues (2'-C-methyladenosine and 2'-O-methyleytidine) which have the "ribo'-sugar moieties in common (Figure 1). Unfortunately, however, there has been little efforts to correlate the HCV RdRp's insensitivity to [DNA polymerase inhibitors with its RNA specificity. Thus, it is of our great interest to find the characteristic structural features of the active site of $\mathrm{HCV}$ RdRp which might be constructed in such a way as to selectively accommodate the RNA substrate. Eventually, understanding the RNA-specificity of HCV RdRp would serve as the key for the future development of novel antiHCV nucleoside analogues. Herein, we report our recent

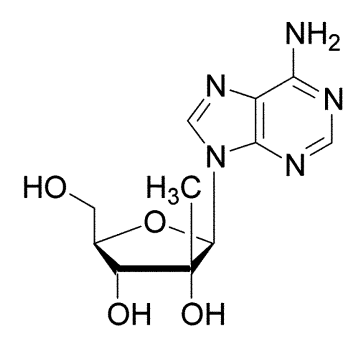

2'-C-Methyladenosine<smiles>COC1C(O)C(CO)OC1n1ccc(N)nc1=O</smiles>

2'-O-Methylcytidine
Figure 1. 2'-Substituted 'ribo'-nucleoside analogues.

efforts to develop potent and selective inhibitors of HCV RdRp by elucidating the structural characteristics of the active site of HCV RdRp.

\section{Experimental Section}

All molecular modeling studies of the enzyme-substrate complexes were carried out using SYBYL 7.0 (Tripos Inc. St. Louis, Mo.) on linux enterprise operating system.

Polymerase Structure. Three dimensional crystal structures of HIV-1 reverse transcriptase and $\mathrm{HCV}$ RNAdependent RNA polymerase were obtained from the protein data bank (PDB code IRTD and IQUV, respectively). The two structures were superimposed by fitting seven amino acid residues around the active site with RMSD (RootMean-Square-Deviation) of $0.89 \AA$ : Arg72 (RT)-Arg158 (RdRp), Aspl10-Asp220, Asp113-Cys223, Alal14-Phe224, Tyr115-Asp225, Asp 185-Asp318, Asp186-Asp319. INA template-primer duplex, two $\mathrm{Mg}$ atoms and TTP (thymidine triphosphate) in RT were then merged into the HCV RdRp active site. DNA template-primer duplex except three pairs from the active site (U-G-G: A-C-C, primer:template) and template overhang were removed for the sake of simplicity, and the DNA pairs were modified into the corresponding RNAs. Gästeiger-Hückel charge ${ }^{11.12}$ was given to the ligand 
with formal charges (+2) to two $\mathrm{Mg}$ atoms in the active site. Then, Kollman- $\Lambda 11-\Lambda$ tom charges ${ }^{33.14}$ were loaded to the enzyme site from the biopolymer option in SYBYL 7.0. In order to sliminate local strains resulting from merging inhibitors, residues inside $8 \AA$ from the merged inhibitors were annealed ${ }^{35}$ until the energy change from one iteration to the next was less than $0.05 \mathrm{kcal} / \mathrm{mol}$ (hot region: $8 \dot{\Lambda}$, interesting region: $12 \AA$ ). The annealed enzyme-inhibitor complexes were minimized by using Tripos force field for 5,000 itcrations.

Modeling Binding Modes of $2^{*}-O$-Methyleytidine and 2'-C-Methyladenosine at the Active Site of RdRp. Crystallographic structure of D-adenosine triphosphate ( $\mathrm{ATP}$, 3 -endo conformation) was used as a template for construction of 3 '-endo conformation of 2'-O-methylcytidine triphosphate (2'-O-Me-CTP) and 2'-C-methyladenosine triphosphate (2'- $\left.{ }^{2}-\mathrm{Mc}-\Lambda T P\right)$. In contrast, the D-adenosine triphosphate was modified into its $2^{\prime}$-endo conformation first to provide the three dimensional models of $2^{\prime}-O$-methylcytidine triphosphate (2*-O-Me-CTP) and $2^{\prime}-C$-methyladenosine triphosphate $\left(2^{\prime}-(-\mathrm{Me}-\Lambda \mathrm{TP})\right.$ in $2^{\prime}$-endo conformation. The modeled nucleoside monophosphate analogues were superimposed into the substrate (UTP, uridine triphosphate) bound at the active site of RdRp, merged and replaced with UTP. The resulting RdRp: $2^{+}-O-\mathrm{Me}-\mathrm{CTP}$ and RdRp: $2^{\prime}-\mathrm{C}-$ Me-ATP complexes were energy-minimized by using the same protocol as described above.

2'-OH Binding Site. Crystallographic water molecules, $\mathrm{RNA}$ duplex and two Mg atoms were removed from the RdRp:ligand complexes and the Connolly surface of the enryme was generated by using the 'Fast Connolly Channel' option in the 'Molcad Surface Generation' menu of Sybyl 7.0. The surface, thus generated, was overlaid with the enyme-RNA duplex complex containing water molecules for investigation of the 2'-OI binding pocket.

\section{Results and Discussion}

Crystal Structure of HCV RdRp. HCV belongs to the Flaviviridoe Jamily, which contains a positive-sense singlestranded RNA. The IICV genomic RNA contains a single open reading frame which encodes a polyprotein precursor of $\sim 3010-3033$ anino acids. The polyprotein precursor is further processed by cellular signal peptidase and virally encoded proteases $t o$ generate three structural (core, F.l, F:2) and seven non-structural (P7, NS2, NS3, NS4A, NS4B, NS5 4 , NS5B) proteins. HCV NS5B is the viral RNAdependent $R N \wedge$ polymerase ( $R d R p$ ) that is responsible for viral genome replication. HCV RdRp contains a total of 591 amino acids and the mutational analysis has suggested that the calalytic core of IICV RdRp is contained in the $\mathrm{N}$ terminal -540 amino acids. ${ }^{16}$ Three groups have reported NS5B structures in the absence of substrates, at $2.8 \dot{\Lambda},{ }^{17} 1.9$ $\lambda_{1}^{18}$ and $2.5 \dot{\Lambda}^{19}$ resolution. In all structures reported, the IICV RdRp protein displays the lingers, palm, and thamb subdomains characteristic of all known RNA and DDNA polymerases as shown in Figure 2. However, unlike other

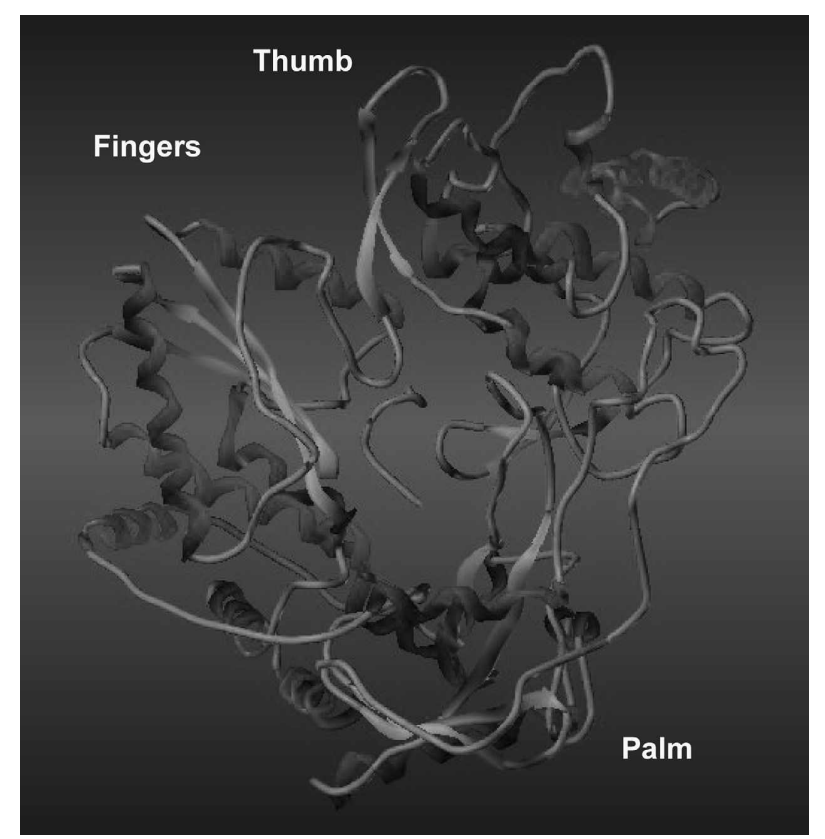

Figure 2. HCV RuRp las three subdomans like otler polymerases, but the lingers and thumb regions completely encireles the actives sile.

polymerases that resemble a right hand and bind $\mathrm{DN} A$ or RNA in a cleft between the lingers and thumb, IICV NS5B has an enlarged thumb and expanded lingers region that completely encircles the active site (Figure 2 ).

HCV RdRp has a "closed" Conformation. It is well known that viral DNA and RNA polymerases undergo conlormational changes upon binding of primed template and substrate at the active site, which accompanics closing the gap between the fingers and the thumb subdomains to make the enzyme catalytically competent. ${ }^{20}$ In the absence of proper substrates, all other polymerases have been observed in an "open" conformation, with the fingers rotated away from the thumb, and they only adopt the "closed" conformation in the presence of a primed template and the proper NTP (nucleoside triphosphate) that is to be next inserted. The crystal structures of $1 \mathrm{ICV} \mathrm{RdRp}^{17-19}$ do not have primed template and substrate, but they represent the catalytically competent confomations of the enryme because IICV RdRp includes an encircled active site with an overall globular shape instead of the typical $\mathrm{U}$ shape found in other polymerases (Figure 2). Such an encircled active site is dec to the extensive interactions between the fingers and the thumb subdomains, which close the gap between the two subdomains. ${ }^{17-19}$

Construction of HCV RdRp-template/Primer-rNTP Ternary Complex. Although none of the crystal structures of HICV RdRp was solved with RNA or metal ions bound to the active site, the residues involved in binding of RNA and metals have been highlighted by superimposition with the temary complex of HIV reverse transeriptase. ${ }^{20}$ For example, two aspartates, $\Lambda$ sp 220 and $\Lambda$ sp318, were found to be the key residues for nucleotide metal binding, consistent with the biochemical data obtained from site-directed 
mutagenesis of IICV RdRp. ". Thus, RNA duplex and metal ions, which are missing from the crystal structure of IICV RdRp but required for ligand binding studies, conld be modeled into the HCV RdRp by adopting those of HIV-I RT after superimposition of the two enzymes. Similarly, both Bressane $1 \mathrm{j}^{17}$ and Lesburg ${ }^{169}$ reported that the DNA duplex of IIIV-1 RT (PI)B code 1RTD) could be used as a template to model RNA duplex into HICV RdRp structures without major conformational changes in the fingers and thamb domains. In our study, DNA template-primer was modeled into IICV RdRp by overlaying IICV RdRp (PDB code IQUV) with IIIV-I RT (PDB code IRTD) around seven matching an ino acid pairs (Figure $3, \wedge \operatorname{rg} 158-\wedge \operatorname{rg} 72 ; \wedge \operatorname{sp} 318-$

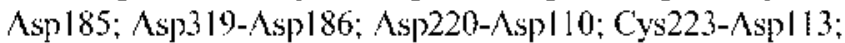
Phe224-Alal 14; $\Lambda$ sp225-Tyrl 15 ) between the two enzymes (RMSI) $0.89 \dot{\lambda}$ ). The modeled IJNA duplex was truncated from the active site leaving three base pairs, which were modilied into the corresponding RNA's. The ternary complex of RT showed that, although the I)NA appears to be predominantly in the B-form, the base pairs close to the polymerase active site have an $\Lambda$-like conformation with a widened minor groove, which is the standard conlomation of RNA duplex. Therefore, A-form DNA duplex around the active site of RT could be successfully used as a template for RNA duplex of HCV RdRp without signilicant conformational change upon modilication. Like other polymerases, IICV RdRp also requires divalent cations for catalysis. The most prefered melals have been identified as $\mathrm{Mg}^{2}$ at concentrations of $-5-10 \mathrm{mM}$ or $\mathrm{Mn}^{2}$ at lower concentrations $(<1 \mathrm{mM})$. The involvement of divalent cations in the reactions catalyred by IICV RdRp can be explained by the two metal ion mechanism established for other DDNA and

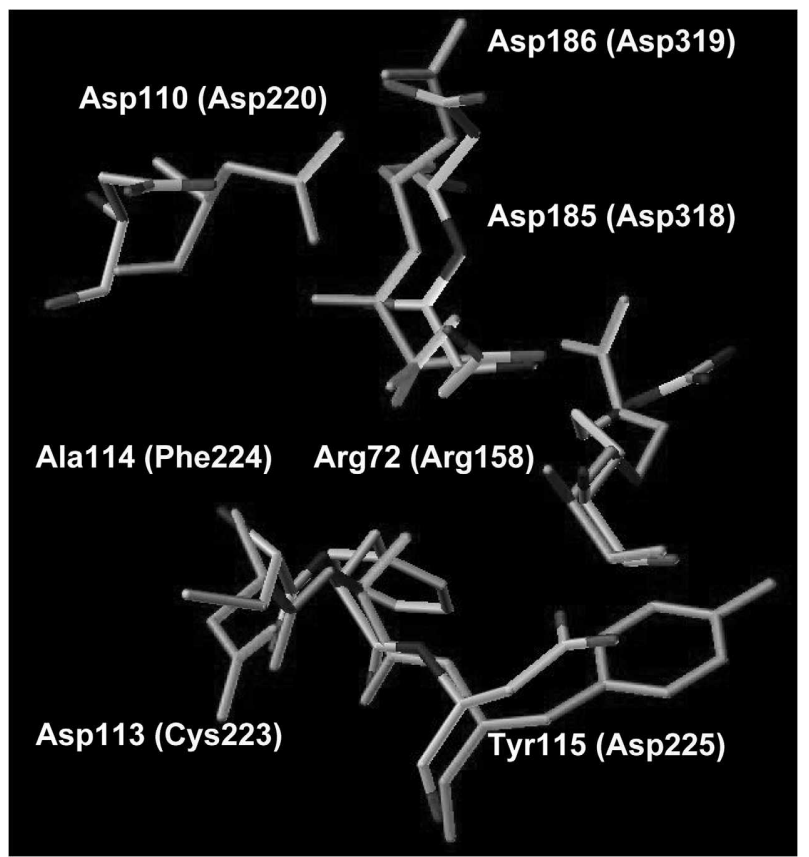

Figure 3, Seven malching amino acid pairs between IIIV-I R'T (green color, white legend) and HCV RdRp (atom type color. yellow legend).
RNA polymerases. ${ }^{22}$ As mentioned above, these metals, together with several conserved aspartates $(\Lambda \mathrm{sp} 220, \Lambda$ sp 319 , Asp3 18), are responsible for coordination of nucleotide binding to the enzyme, and thus, modeled into the active site of the enzyme accordingly (Figure 3 ).

RNA Specificity of HCV RdRp. IJCV NS5B is indeed an RNA-dependent RNA polymerase: it does not contain DNA-dependent RNA polymerase activity or RNA-dependent DNA polymerase (reverse transcriptase) activity because it cannot utilize DNA as template or deoxynucleotide as substrate. ${ }^{10.23}$

Active Site Analysis of HCV NS5B Polymerase: 2-OH Binding Pocket. Fver since the landmark discovery of acyclovir, viral polymerases have been very popular targets for antiviral drugs, which resulted in the wide use of nucleoside analogues for treatment of hepatitis $B$ virus and IIIV infections. ${ }^{24}$ However, it should be noted that the antiviral nucleoside research has been locused on the inhibition of IIIV reverse transeriptase or IIBV polymerase both of which take DNA as substrates. The three dimensional structure of IIIV-I RT ${ }^{20}$ clearly explains how the enzyme achicves its $\Gamma N A-s p e c i f i c t y:$ one of the key active site residues, Tyr 115 does not allow RNA to bind the active site by acting as a "steric gate" against the 2'-OII group of the RNA (Figure 4). Naturally, nucleoside analogues with 2'-OII group have not drawn specilic altention whereas $2^{4}$-deoxy or 2',3'-dideoxy nucleoside analogues played major roles in antiviral nucleoside research. However, in the context of the RNA-specificity of IJCV NS5B RdRp, there must be specilic interaction between the 2'-OHI group of the R.VA substrate and the active site residues. Thus, it was our intention to understand the structural background which

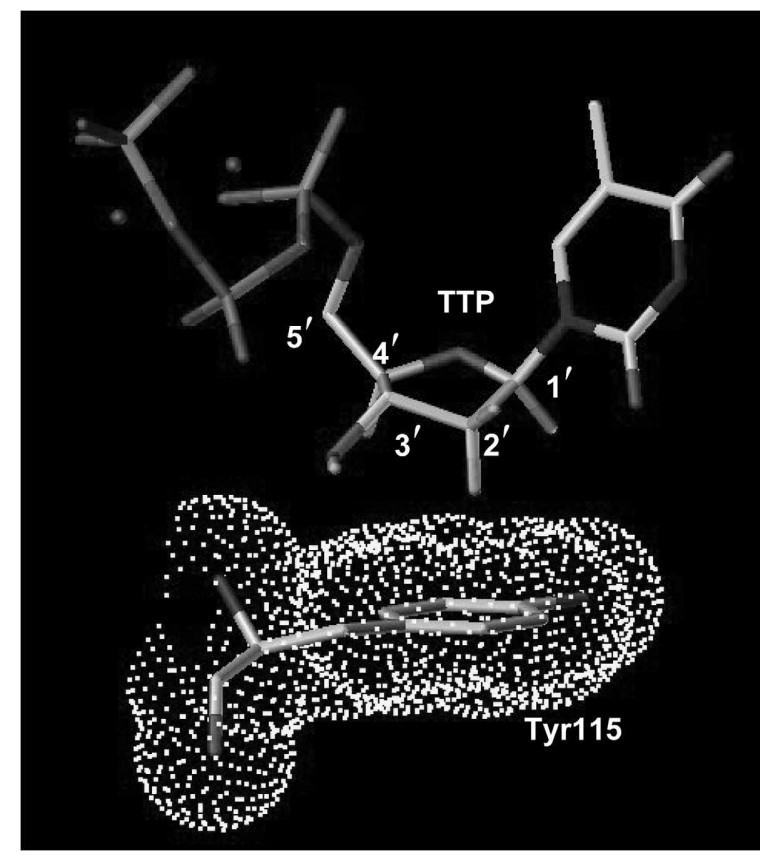

Figure 4. The 'steric gate' of HIV-I RT: The bulky aromatic side clain of Tyr 15 lies right below the 2'-H to prevent ribonucleotides from binding the active site. 


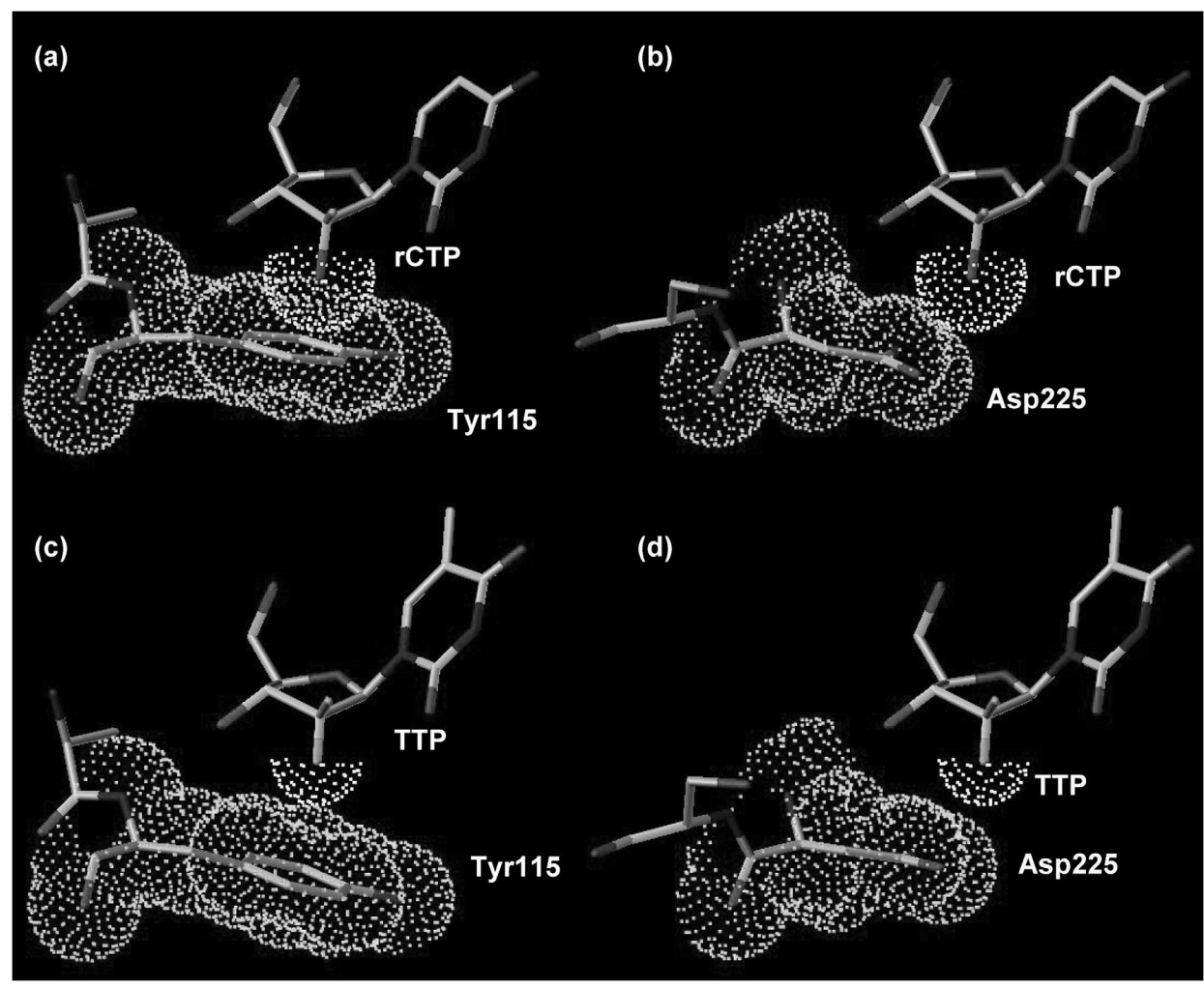

Figure 5. Asp225 of HCV RdRp (b, d) corresponds to the steric gate (Tyrll5) of HIV-I RT (a, c), but the small side chaij of $\Lambda$ sp225 provides enough space to the active site for linding of ribonucleotides. Ribonucleoside rCTP' experiences steric hindrance with the aromatic side chain ol Tyrl15 of R'T (a) but deoxyribonuckoside T'T' is well separaled trom Tyrl 15 (c).

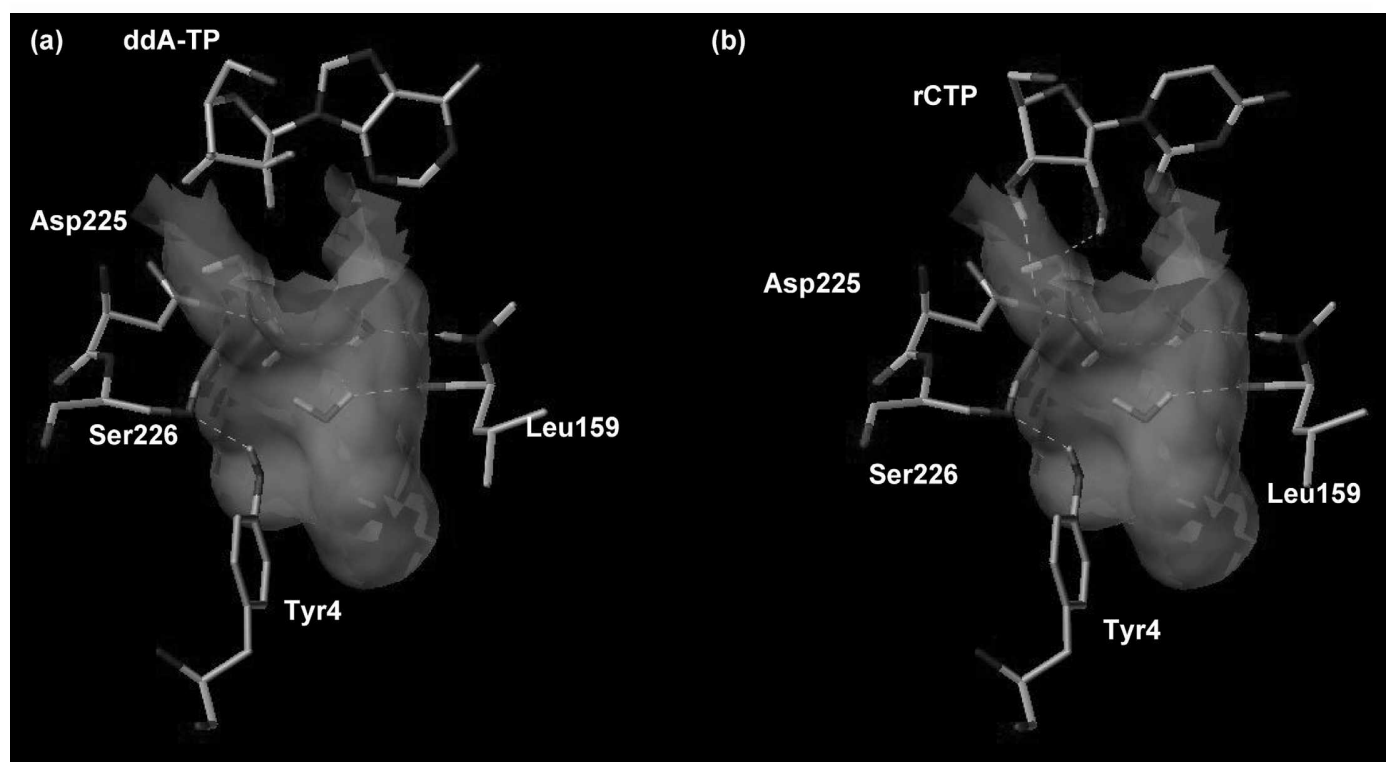

Figure 6. (a) Anti-HIV drug dd $\Lambda$-triphosphate is located at the active site of HCV RdRp. Nucleoside triphosphate does not have any specific interaction with the pocket residues or water molecules inside the pocket (yellow surlace). (b) '2'-OH pocket' (yellow surface) composed of Asp225. Ser226. Tyr4 and 1 esul59 contains water molecules which interact with both the 2'-Ofl of rCTP and pocket residues through hydrogen bonding networks.

supports the RNA-specificity of IICV RdRp for the purpose of designing more potent and specific HCV RdRp inhibitors.

Sequence alignment showed that the "steric gate" of IIJV1 RT (Tyr1 15) corresponds to Asp225 in IICV RdRp (Figure $3)$, but the small side chain of $\Lambda$ sp225 provides an open space at the active site enough to accommodate the ribose sugar moiety of RNA substrale (Figure 5). The side chain carboxylate of $\Lambda \mathrm{sp} 225$ is in close proximity to the $3-\mathrm{OH}$ of rNTP (ribonuclcoside triphosphatc), which is reminiscent of the hydrogen bonding interaction between the amide 


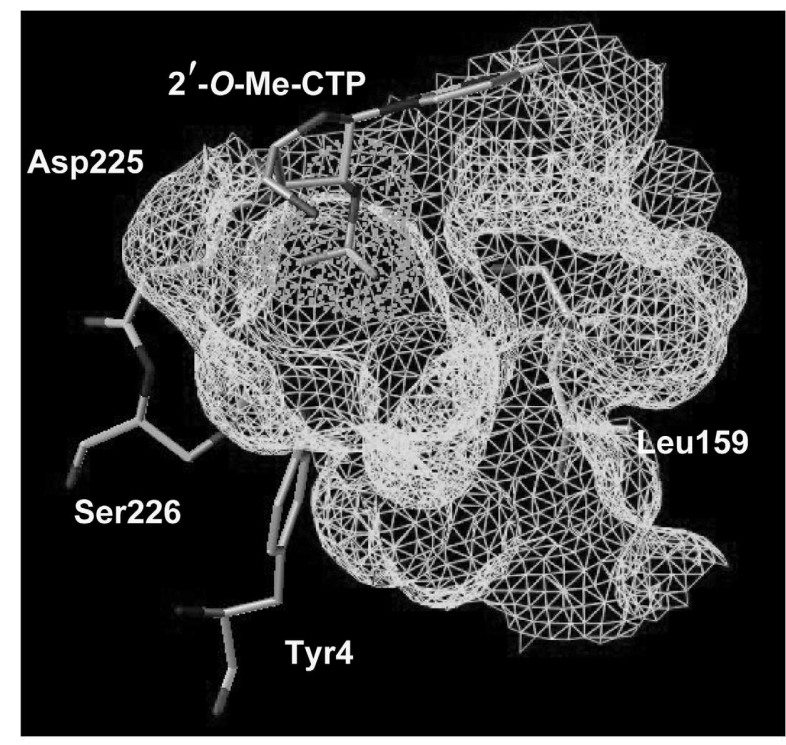

$$
\text { Cytosine }
$$

Figure 7.2'-O-methyl group of 2'-O-Me-CTP can be localed inside the "2'-OH pocke" through valn des Waals interaction with the pocket residues. 2'-substituents with higher steric demands than methyl looks to be aceommodaled by the pocket. South (2'-endo) contormation of 2 '-O-Me-CTP (right) was used for binding siludy.

backbone of Tyrl15 and 34-OHT of NTP in HIV-I RT structure (Figure 5). However, no active site residue could be found close to the 2'-OII group of rNTP for specilic interaction, which did not support our assumption that the 2*OII group must be involved in the RNA-specificity of IICV RdRp. Thus, the only way by which the 2'-OI group could achieve a specific interaction with the enzyme residue secmed to be by way of bridging water molecules inside the active site. To our surprise, crystallographic water molecules could be found around the 2'-OII group of the R.VA substrate and more interestingly, those water molecules were tightly held at the middle of an $11 \lambda$ long channel located next to $\Lambda$ sp225 (Figure 6 ). The hereto unknown active site channel is composed of 11 residues, which are in excellent three dimensional arrangements to hold water molecules. The water molecules act either as a hydrogen bond donor or an acceptor to the 2'-OII group of the RNA substrate (Figure 6). In addition to the critical role in the binding of the R.NA substrate, the pocket provides more important insights into the design of potent and specilic inhibitors of HICV RdRp. First, we could understand the characteristic binding modes of 2'-O-Me-CTP and 2'-C-Me-ATP, which are the most potent two nuclcoside analogues developed so lar. Recently, two separate studies ${ }^{25.26}$ suggested that 2'-O-methylcytidine and $2^{\prime}-C^{-}$-methyladenosine would have south $\left(2^{+}\right.$-endo) and north (3'-endo) conlormations, respectively (Figures 7 and

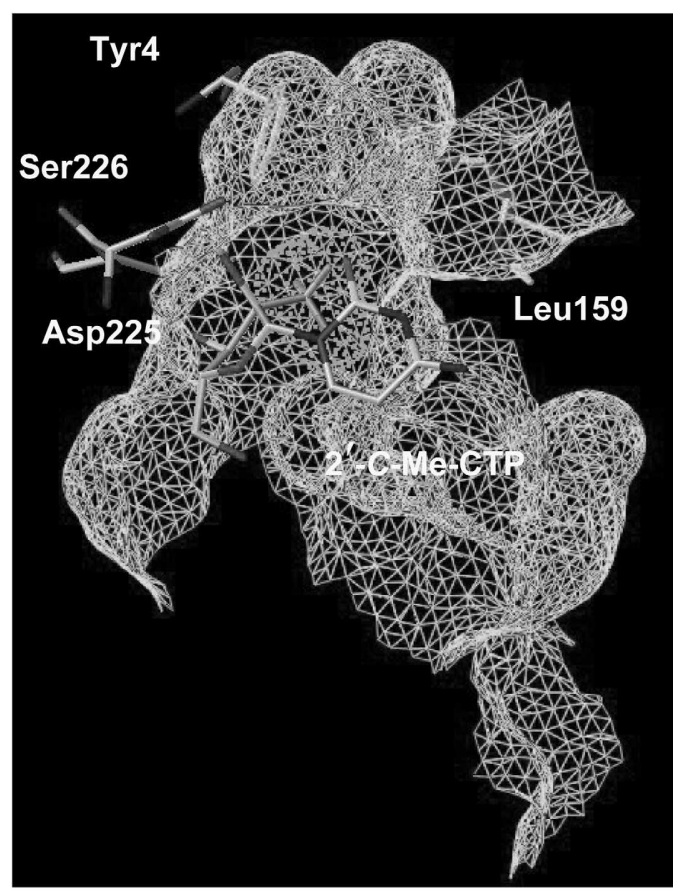<smiles>CC1(CO)OC2C(O)C1C2CO</smiles>

Figure 8. Top view of the binding mode of $2^{\prime}-\mathrm{C}^{-}-\mathrm{Me}-\mathrm{CTP}^{\prime}$ at the active site of HCV RdRp. 2'-C-methyl substituent is well-oriented just inside the $2^{2}-\mathrm{OH}$ pocket for stable binding interaction (van der Waals) with the pocket residues. North (3'-endo) conformation of 2'-C-Mc-CTP (right) was used for binding sludy.

$8)$. It was intriguing that only the south (2'-endo) conformation of 2 -O-methylcytidine could be suceesslully located at the active site of JICV RdRp (Figure 7) while the north ( $3^{\dagger}$-endo) conformation experienced severe steric hindrance between its sugar moicty and the active site residues. In addition, 2'-O-methyladenosine $\left(2^{\prime}\right.$-endo) showed its $2-O$ methyl group located in the middle of the 2'-OIl pocket of the enzyme, which provides an interesting insight into designing more potent HCV RdRp inhibitors (Figure 7). As the $\| \dot{\lambda}$ long pocket has residues with polar side chains in the middle for coordination of water molecules, longer $2-O$ substituents capable of electrostatic interaction with the pocket residues would have greater chance to selectively bind to the active site of HCV RdRp. In contrast, $2^{\prime}-C$ methyl group of 2'-C-methyladenosine looks like to be the substituent of choice because the 2 - $C$-methyl snuggly lits into a small groove at the top of the 2'-Oll poeket when the sugar moricty adopts north (3'-endo) conformation (Figure 8 ), which is in good accordance with the poor antiviral activity of $2^{+}$-Cethyladenosins. ${ }^{25}$ The south $\left(2^{\prime}\right.$-endo) conformation of '2'-C-methyladenosine results in an abortive binding mode due to the lack of any specilic interaction with the active site residues. 


\section{Conclusion}

Unlike other viral polymerases, HCV RNA-dependent RNA polymerase (RdRp) has not been successfully inhibited by nucleoside analogues presumably due to its strong substrate specificity for RNA. In this study, the RNAspecificity of $\mathrm{HCV}$ RdRp was investigated by molecular modeling studies to give information about the existence of the hereto unknown $2-\mathrm{OH}$ binding pocket at the active site of RdRp, which provides invaluable implication for the development of novel anti-HCV nucleoside analogues.

Acknowledgments. This work was supported by the faculty research fund of Konkuk University in 2005.

\section{References}

1. Alter. M. J.; Kruszon-Moran, D.; Nainan. O. V.; McQuillan. G. M.; Gao, F.; Moyer, L. A.; Kaslow, R. A.; Margolis, H. S. N. Engl. J. Med. 1999, 341, 556-562.

2. Choo, Q.-L.; Kuo, G.; Weiner, A. J.; Overby, R. L.; Bradley, D. W. Houghton, M. Science 1989, 244, 359-362.

3. Saito, I.; Miyamura, T.; Ohbayashi, A.; Katayama, T.; Kikuchi, S.; Watanabe, Y.; Koi, S. Proc. Natl. Acad. Sci. U.S.A. 1990, 87. $6547-6549$.

4. Hwang, S. B.; Park, K.-J.; Kim, Y.-S.; Sung, Y. C.; Lai, M. M. C, Virolog: 1997, 227, 439-446.

5. Behrens, S.-E.; Tomei, L.; De Francesco, R, EMBO J. 1996, 15, $12-22$.

6. Takamizawa, A.; Mori, C.; Fuke, I.; Manabe, S.; Murakami, S.; Fujita, J.; Onishi, E.; Andoh, T.; Yoshida, I.; Okayama, H. J. Virol. $1991,65,1105-1113$

7. Kim, J.; Lee, M.; Kim, Y.-Z. Bndl. Korean. Chem. Soc. 2005, 26, 285.

8. Ishii, K.; Tanaka, Y.; Yap, C. C.; Aizaki, H.; Matsuura, Y.; Miyamura, T. Hepatology 1999, 29, 1227-1235.

9. Ferrari, E.; Wright-Minogue, J.; Fang, J. W.; Baroudy, B. M.; Lau. J. Y.; Hong, Z. J. Virol. 1999, 73, 1649-1654.
10. Johnson, R. B.; Sun, X. L.; Hockman, M. A.; Villarreal, E. C.; Wakulchik, M.; Wang, Q. M. Arch. Biochem. Biophys. 2000, 377, 129-134.

11. Gästeiger, J.; Marsili, M. Tetrahtedron 1980, 36, 3219-322.

12. Purcell, W. P.; Singer, J. A. J. Chem. Eng. Data 1967, I2, 235246.

13. Blaney, J. M.; Weiner, P. K.; Dearing, A.; Kollman, P. A.; Jorgensen, E. C.; Oatley, S. J.; Buridge, J. M.; Blake, C. C. F. J. Am. Cheni. Soc. 1982, 104, 6424-6434.

14. Wipff, G.; Dearing, A.; Weiner, P. K.; Blaney, J. M.; Kollman, P. A. J. Am. Chem. Soc. 1983, 105,997-1005.

15. Chong, Y.; Bortoto-Esoda, K.; Furman, P. A.; Schinazi, R. F.; Chu, C. K. Antivir. Chen. Chemother. 2002, I3, 115-128.

16. Tomei, L.; Vitale, R. L.; Incitti, I.; Serafini, S.; Altamura, S.; Vitelli, A. J. Gen. Virol. 2000, 81, 759-767.

17. Bressanelli, S.; Tomei, L.; Roussel, A.; Incitti, I.; Vitale, R. L.; Mathieu, M. Proc. Natl. Acad. Sci. U.S.A. 1999, 96, 13034-13039.

18. Ago, H.; Adachi, T.; Yoshida, A.; Yamamoto, M.; Habuka, N.; Yatsunami. K. Stricture Fold Des. 1999. 7. I4I 7-1426.

19. Lesburg, C. A.; Cable, M. B.; Ferrari, E.; Hong, Z.; Mannarino, A. F.; Weber, P. C. Nat. Siruct. Biol. 1999, 6, 937-943.

20. Huang, H.; Chopra, R.; Verdine, G. L.; Harrison, S. C. Science $1998,282,1669-1675$.

2I. Lohmann, V.; Komer, F.; Herian, U.; Bartenschlager, R. J. Virol. 1997. 71.8416-8428.

22. Steitz, T. A. J. Biol. Chem. 1999, 274, 17395-17398.

23. Yamashita, T.; Kaneko, S.; Shirota, Y.; Qin, W; Nomura, T.; Kobayashi, K. J. Biol. Chen. 1998, 273, 15479-15486.

24. Chu, C. K. Antivinal Nucleosides: Chiral Symthesis and Chemotherapy; Elsevier: Amsterdam, Neth., 2003.

25. Tomassini, J. E.; Getty, K.; Stahlhut, M. W.; Shim, S.; Bhat, B.; Eldrup. A. B.; Prakash, T. P.; Carroll. S. S.; Flores, O.; MacCoss, M.; McMasters, D. R.; Migliaccio, G.; Olsen, D. B. Antinticrob. Agents Chemother. 2005, 49, 2050-2058.

26. Eldrup, A. B.; Prhavc, M.; Brooks, J.; Bhat, B.; Prakash, T. P.; Song, Q.; Bera, S.; Bhal, N.; Dande, P.; Dan Cook, P.; Bennetl, C. F.; Carroll, S. S.; Ball, R. G; Bosserman, M.; Burlein, C.; Colwell, L. F.; Fay, J. F.; Flores, O. A.; Getty, K.; LaFemina, R. L.; Leone, J.; MacCoss, M.; McMasters, D. R.; Tomassini, J. E.; Von Langen, D.; Wolanski, B.; Olsen, D. B. J. Med. Chem. 2004, 47, 52845297 . 